\title{
Successful Management of a Pregnant Patient With Chronic Myeloid Leukemia Receiving Standard Dose Imatinib
}

\author{
STEFANIA STELLA ${ }^{1,2^{*}}$, ELENA TIRRÓ $^{1,2^{*}}$, MICHELE MASSIMINO $^{1,2^{*}}$, \\ SILVIA RITA VITALE ${ }^{1,2}$, SABINA RUSSO $^{3}$, MARIA STELLA PENNISI $^{1,2}$, \\ ADRIANA PUMA $^{1,2}$, CHIARA ROMANO $^{1,2}$, SANDRA DI GREGORIO $^{1,2}$, VANESSA INNAO $^{3}$, \\ FABIO STAGNO $^{4}$, FRANCESCO DI RAIMONDO ${ }^{4,5}$, CATERINA MUSOLINO $^{3}$ and LIVIA MANZELLA ${ }^{1,2}$ \\ ${ }^{1}$ Department of Clinical and Experimental Medicine, University of Catania, Catania, Italy; \\ ${ }^{2}$ Center of Experimental Oncology and Hematology, A.O.U. Policlinico-Vittorio Emanuele, Catania, Italy; \\ ${ }^{3}$ Division of Hematology, University of Messina, Messina, Italy; \\ ${ }^{4}$ Division of Hematology and Bone Marrow Transplant, A.O.U. Policlinico-Vittorio Emanuele, Catania, Italy; \\ ${ }^{5}$ Department of Surgery, Medical and Surgical Specialities, University of Catania, Catania, Italy
}

\begin{abstract}
Background/Aim: As approximately 10\% of individuals developing chronic myeloid leukemia $(C M L)$ are females aged 20-44 years, a considerable number will consider a planned pregnancy if disease is well controlled by pharmacological treatment. The management of these young patients during pregnancy represents a therapeutic dilemma due to the potential teratogen effects of several tyrosine kinase inhibitors (TKIs) and is a matter of continuous debate. Indeed, despite the existence of several studies, there is currently no consensus on how to manage different pregnancy situations in subjects with CML. Patients and Methods: We describe a female patient diagnosed with Ph-positive CML one month after her first delivery who achieved excellent hematological, cytogenetic and molecular responses while on imatinib mesylate (IM) treatment. Results: The excellent responses allowed the patient to suspend TKI treatment in order to plan a second pregnancy. Despite IM discontinuation, stringent molecular monitoring of her BCR-ABL1/ABL1 levels allowed the safe delivery of the child and, while the patient eventually developed a molecular relapse after four years of treatment
\end{abstract}

This article is freely accessible online.

*These Authors contributed equally to this work.

Correspondence to: Stefania Stella, University of Catania Department of Clinical and Experimental Medicine, Center of Experimental Oncology and Hematology. Building 8D/2 - Via Santa Sofia, 78, 95123, Catania, Italy. Tel: +39 0953781946, Fax: +39 0953781949, e-mail: stefania.stel@gmail.com

Key Words: Pregnancy, chronic myeloid leukemia, BCR-ABL1, imatinib mesylate. discontinuation, upon restarting IM she quickly regained a deep molecular response that is still ongoing. Conclusion: Our case report demonstrates that, if the pregnancy is properly planned in CML patients, it can result in excellent management of the clinical therapeutic option for the benefit of both mother and child.

The Philadelphia $(\mathrm{Ph})$ chromosome, generated by the reciprocal translocation of the $B C R$ gene at $22 \mathrm{q} 11$ and the $A B L 1$ gene at $9 \mathrm{q} 34$, is the cytogenetic culprit of chronic myeloid leukemia (CML) (1-3). At the molecular level, the $\mathrm{Ph}$ chromosome generates the $B C R-A B L 1$ chimeric oncogene encoding for a protein with constitutive tyrosine kinase activity that alters the proliferation rate, survival signaling, immunological interactions and cytoskeleton dynamics of the hematopoietic stem cells (4-8). The development of $B C R$ $A B L 1$ tyrosine kinase inhibitors (TKIs) over the past 20 years has significantly improved the outcomes for patients at every stage of $\mathrm{Ph}+$ chromosome CML. Despite these achievements, the emergence of $B C R-A B L 1$ TKI resistant clones represents a major hurdle for the successful treatment of $\mathrm{Ph}+$ leukemias, requiring often alternative therapeutic approaches (9-13). To data the standard care for chronic-phase CML patients is imatinib mesylate (IM), a semi-specific $B C R$ - $A B L 1$ TKI. The introduction of IM in clinical practice has dramatically generated unprecedented rates of complete hematological (CHR), cytogenetic (CCyR) and molecular responses (MR) (14-18).

CML accounts for approximately $15 \%$ of all adult leukemias with an incidence of about 1 case per 100,000 individuals. Although the median age at diagnosis is 56 years, approximately $17 \%$ of cases occur in the range between 20 and 44 years. Therefore, young female CML patients are likely to consider the possibility of giving birth 
to one or more children during their lifetime $(19,20)$. Nevertheless, to date there is still no consensus on how to properly manage pregnancy in female patients with CML. In general, TKI treatment is not recommended during pregnancy due to the teratogen effect of these drugs $(21,22)$.

In the present report, we describe a patient diagnosed with chronic-phase Ph-positive CML one month after her first delivery who exhibited an optimal response to standard dose IM according to the 2013 European LeukemiaNet recommendations (23). Her excellent molecular response allowed IM discontinuation in order to plan a second pregnancy.

\section{Case Report}

In January 2006, a 30-year-old female was referred to our hospital one month after her first delivery with abnormal blood cell counts. At the time, her hemoglobin (Hgb) was 13.2 $\mathrm{g} / \mathrm{dl}$ with 29.500 white blood cells (WBC) (64\% neutrophils, $16 \%$ lymphocytes, $4 \%$ eosinophils, 3\% basophils, $1 \%$ monocytes, $6 \%$ promyelocytes, $1 \%$ metamyelocytes, $4 \%$ myelocytes and 1\% myeloblasts) and 797.000 platelets (Plt). The spleen was palpable $2 \mathrm{~cm}$ below the left costal margin while liver size was normal.

Conventional cytogenetics detected the $\mathrm{Ph}$ chromosome in all examined metaphases [karyotype 46, XX, t(9;22)(q34;q11)] and a FISH analysis showed the presence of $B C R-A B L 1$ in $95 \%$ of interphase nuclei. Both conventional cytogenetics and FISH showed chromosome 9 deletion in $30 \%$ of the Phnegative chromosomes examined. Multiplex reverse transcriptase (RT)-PCR detected the e14a2 BCR-ABL1 transcript (Figure 1A) with an e1a2 $B C R-A B L 1$ variant barely noticeable by nested RT-PCR. At this time, amplification of the oncogenic transcripts was carried out by Real Time quantitative PCR (Q-PCR) and detected $B C R-A B L 1 / A B L 1$ levels of $71.72 \%$ (Figure 1B).

Based on these clinical findings the patient was diagnosed with chronic phase CML and was classified as a low Sokal score (24) and low Hasford score (25). Soon thereafter, she began IM $400 \mathrm{mg} /$ day achieving complete hematological and cytogenetic remissions within 3 months and a major molecular response (MR3) after 6 months of IM (BCR$A B L 1 / A B L 1^{I S}=0.05050$; Figure $\left.1 \mathrm{~B}\right)$. Molecular follow up for the e14a2 transcript was continued every 3 months with QPCR as previously described (26), while nested RT-PCR was employed for the e1a2 variant with failure to amplify this variant after 6 months of therapy. However, in November 2006 the patient had to suspend IM because of grade II liver toxicity (Aspartate Aminotransferase $<200 \mathrm{mU} / \mathrm{ml}$ and Alanine Aminotransferase $<300 \mathrm{mU} / \mathrm{ml}$ ). Although, the patient maintained both her CHR and CCyR, we observed an increase of her p210 BCR-ABL1/ABLI ${ }^{I S}$ levels (7.512\%) (Figure 1B) and the nested RT-PCR successfully not amplified the e1a2 variant. Mutational analysis failed to detect any kinase domain mutations in their Ph-positive clones. Hence, in January 2007 she restarted IM 400 mg/day and after 6 months she achieved a deep molecular response $\mathrm{MR}^{4}\left(B C R-A B L 1 / A B L I^{I S}=0.00465 \%\right)$ (Figure 1B).

Over the next 4 years, the patient exhibited deep molecular responses varying between $\mathrm{MR}^{4}$ and $\mathrm{MR}^{4.5}$. In July 2011, she approached us wishing to plan a second pregnancy. After careful consideration, we agreed to discontinue IM as long as she would adhere to a strict monthly molecular follow-up as we feared a rapid rise in her oncogenic transcripts after TKI cessation. However, she maintained molecular responses between $\mathrm{MR}^{4}$ and MR4.5 even in the absence of IM (Figure 1B) and, at 38 weeks (April 2012), delivered via cesarean section a healthy baby girl (weight $2,92 \mathrm{~kg}$; height $48 \mathrm{~cm}$; APGAR 9). As her $\mathrm{MR}^{4}$ was stable after giving birth to her second child, she decided to prolong IM discontinuation and remained TKI-free until January 2015 when she lost her major molecular response $\left(B C R-A B L 1 / A B L 1^{I S}=0.12534 \%\right.$; Figure 1B). At this time, she restarted IM and, after 6 months, again attained an $\mathrm{MR}^{4}$ that is ongoing at the present time.

Total RNA was extracted from peripheral blood or bone marrow leucocytes, using the RNeasy mini kit (Qiagen, Hilden, Germany), according to the manufacturer's protocol. cDNA synthesis was carried out using Moloney Murine Leukemia Virus Reserve Transcriptase (Life Technologies, Carlsbad, CA, USA). Cytogenetic analysis performed by G-banding (27) and FISH analysis carried out as previously reported (28). The detection of different $B C R-A B L 1$ fusion transcripts was performed using multiplex reverse transcriptase protocol able to identify contemporary multiplex $B C R-A B L 1$ isoforms $(29,30)$.

The e14a2 $B C R-A B L 1$ fusion transcripts were quantified by Q-PCR according to the suggested recommendations (31) and molecular analysis was performed as previously reported (32). Mutation analysis of the ABL kinase domain by clonal sequencing was performed as previously described (33).

\section{Informed Consent}

Informed consent was received from the patient for the publication of the report as specified in the Declaration of Helsinki.

\section{Discussion and Conclusion}

Pregnancy management in female patients diagnosed with chronic phase CML is a matter of debate and represents a therapeutic dilemma due to the potential teratogen effects of different TKIs. Indeed, several studies have highlighted the risk of embryo-fetal toxicity caused by some $A B L 1$ kinase inhibitors resulting in skeletal malformations, spontaneous abortion, and fetal growth restriction $(34,35)$. 
A

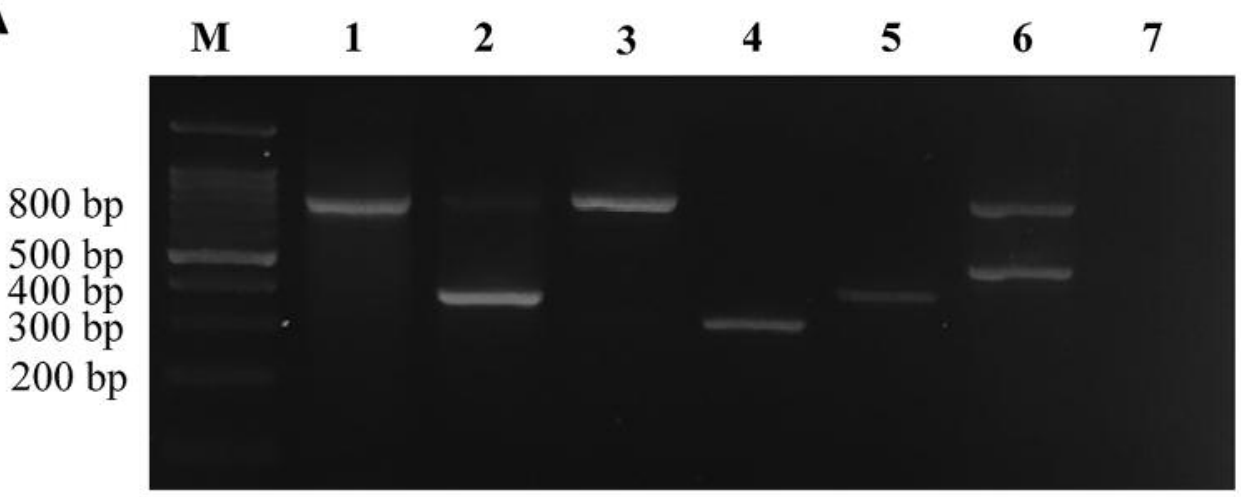

B

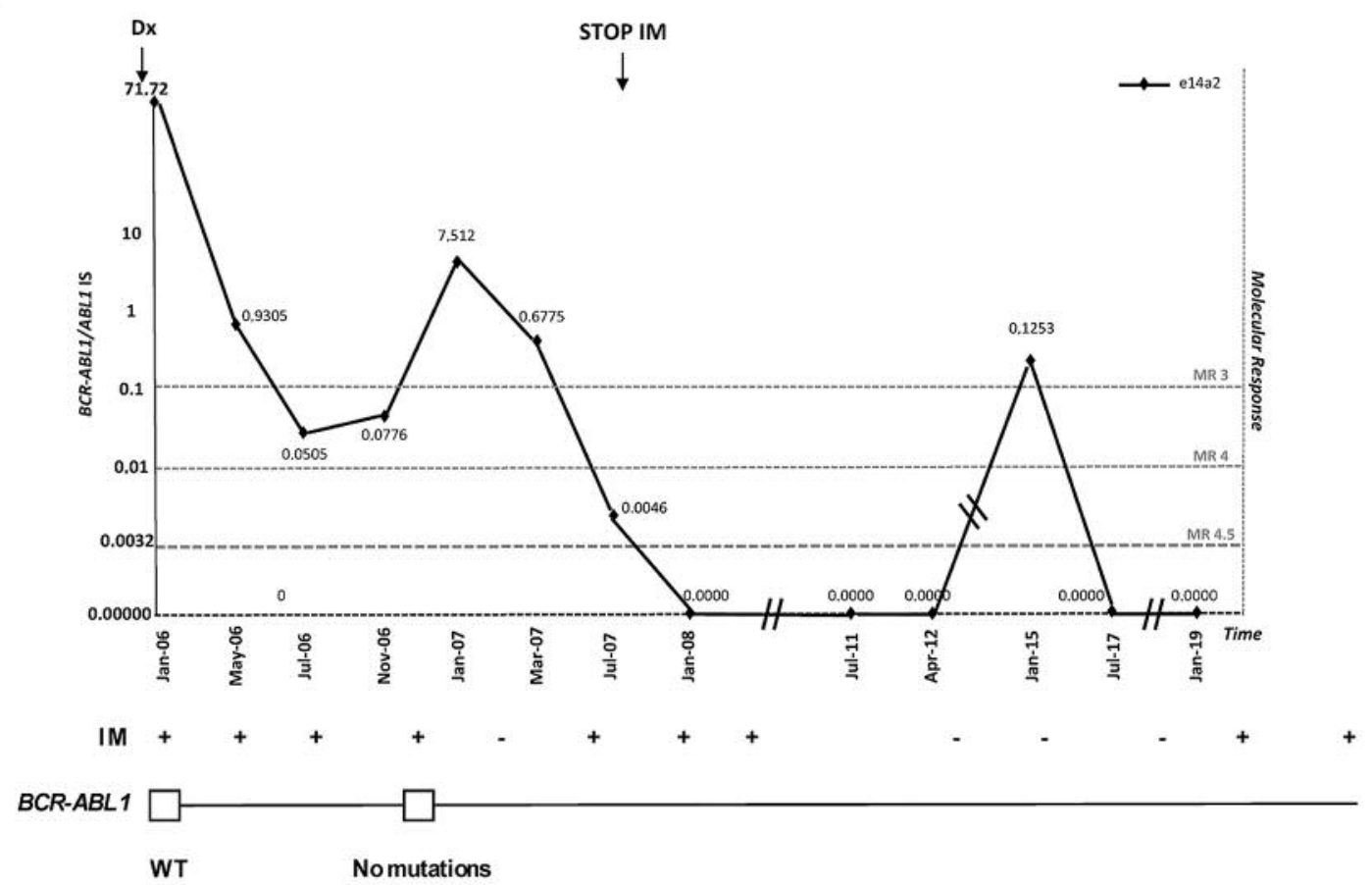

Figure 1. A. Multiplex RT-PCR analysis of the different BCR-ABL1 fusion transcripts. Lane M: Molecular size marker (100-bp ladder); lane 1: patient negative for CML; lane 2: e14a2 (385 bp) from patient; lane 3: patient negative for CML; lane 4: e13a2 (310 pb) positive control; lane 5: el4a2 positive control; lane 6: ela2 positive control; lane 7: negative control. B. Molecular response to IM. Monitoring of patient's disease evolution indicates variations in e14a2 transcripts and drug treatment (top panel) or BCR-ABL1 mutant clones (middle panel). Dotted lines represent achievement of a major (MR3) or a deep molecular response (MR4; MR4.5). A white square indicates wild-type BCR-ABL1. IM: Imatinib.

At the present time, there are no consensus guidelines regarding the management of a pregnancy in CML patients. Experts in the field are only suggest that female subjects still in their reproductive age should be informed about the risks of an unintended pregnancy during TKI therapy and be encouraged to carefully discuss family planning with their physician. A pregnancy should be considered after achieving durable and complete cytogenetic responses followed by equally enduring major molecular responses for at least 1824 months $(20,34)$. Under these circumstances, TKI therapy should be discontinued shortly before ovulation and $B C R$ $A B L 1 / A B L 1$ levels should be monitored on a monthly basis $(34,35)$. In case of cytogenetic or hematological relapses occurring during pregnancy, each physician will have to 
evaluate patient clinical history, rapidity of disease relapse and pregnancy status (period of gestation) in order to advise the mother as to the most appropriate way to proceed.

In this study, we report the case of a female patient diagnosed with CML that rapidly achieved hematologic, cytogenetic, and molecular responses on IM treatment and therefore wanted to consider a second pregnancy. Several reports have shown that women with CML can successfully deliver healthy babies with careful planning and strict disease monitoring.

In our case, the decision to discontinue TKI therapy was further supported by recent findings indicating that patients who achieve and maintain a deep molecular response ( $\geq$ MR4) may be considered for TKI discontinuation as they could remain in treatment-free remission (TFR) even after drug cessation. Indeed, TFR is an attractive possibility for all CML patients as it often provides significant relief from TKI toxicities and general improvements in quality-of-life $(36,37)$. TFR is now considered for many young patients affected by CML and also an end point for some clinical trials. We think that the optimal management of pregnancy in CML is another good reason for pursuing clinical studies aimed to find the best way to manage TFR.

In the last eighteen years, TKIs have radically transformed the management of CML that usually becomes a lifelong chronic condition. However, the management of a planned pregnancy in CML patients requires a thorough evaluation of both risks and benefits that should be carefully discussed between the patient and her physician. To avoid potential teratogenicity to the fetus, it is necessary to find a balance between the mother's childbearing desire and the optimal pharmacological treatment required by the disease. Our case report demonstrated that, if the pregnancy is properly planned, it can result in excellent outcomes for both the mother and child.

\section{Conflicts of Interest}

The Authors declare that they have no competing interests regarding this study.

\section{Authors' Contributions}

SS, ET and MM designed and performed the experiments; SS, ET, MM, SRV, MSP, AP CR and SDR analyzed and interpreted the data; SS wrote the paper; SR, FS, FDR, CM and LM made a critical revision of paper; LM conceived the original idea and supervised the project.

\section{References}

1 Radujkovic A, Topaly J, Fruehauf S and Zeller WJ: Combination treatment of imatinib-sensitive and -resistant bcr-abl-positive $\mathrm{cml}$ cells with imatinib and farnesyltransferase inhibitors. Anticancer Res 26(3A): 2169-2177, 2006. PMID: 16827161.
2 Stagno F, Vigneri P, Del Fabro V, Stella S, Cupri A, Massimino M, Consoli C, Tambe L, Consoli ML, Antolino A and Di Raimondo F: Influence of complex variant chromosomal translocations in chronic myeloid leukemia patients treated with tyrosine kinase inhibitors. Acta Oncol 49(4): 506-508, 2010. PMID: 20331405. 10.3109/02841861003660031

3 Massimino M, Consoli ML, Mesuraca M, Stagno F, Tirro E, Stella S, Pennisi MS, Romano C, Buffa P, Bond HM, Morrone G, Sciacca L, Di Raimondo F, Manzella L and Vigneri P: Irf5 is a target of bcr-abl kinase activity and reduces $\mathrm{cml}$ cell proliferation. Carcinogenesis 35(5): 1132-1143, 2014. PMID: 24445143. DOI: $10.1093 /$ carcin/bgu013

4 Ren R: Mechanisms of bcr-abl in the pathogenesis of chronic myelogenous leukaemia. Nat Rev Cancer 5(3): 172-183, 2005. PMID: 15719031. DOI: 10.1038/nrc1567

5 Stella S, Tirro E, Conte E, Stagno F, Di Raimondo F, Manzella $\mathrm{L}$ and Vigneri P: Suppression of survivin induced by a bcrabl/jak2/stat3 pathway sensitizes imatinib-resistant $\mathrm{cml}$ cells to different cytotoxic drugs. Mol Cancer Ther 12(6): 1085-1098, 2013. PMID: 23536723. DOI: 10.1158/1535-7163.MCT-12-0550

6 Giallongo C, Tibullo D, La Cava P, Branca A, Parrinello N, Spina P, Stagno F, Conticello C, Chiarenza A, Vigneri P, Palumbo GA and Di Raimondo F: Brit $1 / \mathrm{mcph} 1$ expression in chronic myeloid leukemia and its regulation of the $\mathrm{g} 2 / \mathrm{m}$ checkpoint. Acta Haematol 126(4): 205-210, 2011. PMID: 21934293. DOI: $10.1159 / 000329911$

7 Preyer M, Vigneri P and Wang JY: Interplay between kinase domain autophosphorylation and f-actin binding domain in regulating imatinib sensitivity and nuclear import of bcr-abl. PLoS One 6(2): e17020, 2011. PMID: 21347248. DOI: 10.1371/ journal.pone.0017020

8 Manzella L, Tirro E, Pennisi MS, Massimino M, Stella S, Romano C, Vitale SR and Vigneri P: Roles of interferon regulatory factors in chronic myeloid leukemia. Curr Cancer Drug Targets 16(7): 594-605, 2016. PMID: 26728039.

9 Rosti G, Castagnetti F, Gugliotta G and Baccarani M: Tyrosine kinase inhibitors in chronic myeloid leukaemia: Which, when, for whom? Nat Rev Clin Oncol 14(3): 141-154, 2017. PMID: 27752053. DOI: $10.1038 /$ nrclinonc.2016.139

10 Buffa P, Romano C, Pandini A, Massimino M, Tirro E, Di Raimondo F, Manzella L, Fraternali F and Vigneri PG: Bcr-abl residues interacting with ponatinib are critical to preserve the tumorigenic potential of the oncoprotein. FASEB J 28(3): 12211236, 2014. PMID: 24297701. DOI: 10.1096/fj.13-236992

11 Stagno F, Vigneri P, Del Fabro V, Stella S, Restuccia N, Giallongo C, Massimino M, Berretta S, Pennisi MS, Tibullo D, Tirro E, Buscarino C, Messina A and Di Raimondo F: Concomitant and feasible treatment with dasatinib and the antiegfr antibody cetuximab plus radiotherapy in a CML patient with multiple squamous neoplasias. Acta Oncol 49(1): 109-110, 2010. PMID: 19842797. DOI: 10.3109/02841860903302913

12 Stagno F, Vigneri P, Del Fabro V, Stella S, Massimino M, Berretta S, Cupri A, Consoli C, Messina L, Tirro E, Messina A and Di Raimondo F: Successful nilotinib therapy in an imatinibresistant chronic myeloid leukemia patient displaying an intronderived insertion/truncation mutation in the bcr-abl kinase domain. Leuk Res 33(9): e157-158, 2009. PMID: 19406471. DOI: 10.1016/j.leukres.2009.03.040

13 Massimino M, Stella S, Tirro E, Romano C, Pennisi MS, Puma A, Manzella L, Zanghi A, Stagno F, Di Raimondo F and Vigneri 
P: Non ABL-directed inhibitors as alternative treatment strategies for chronic myeloid leukemia. Mol Cancer 17(1): 56, 2018. PMID: 29455672. DOI: 10.1186/s12943-018-0805-1

14 Hochhaus A, Larson RA, Guilhot F, Radich JP, Branford S, Hughes TP, Baccarani M, Deininger MW, Cervantes F, Fujihara S, Ortmann CE, Menssen HD, Kantarjian H, O'Brien SG, Druker BJ and Investigators I: Long-term outcomes of imatinib treatment for chronic myeloid leukemia. N Engl J Med 376(10): 917-927, 2017. PMID: 28273028. DOI: 10.1056/NEJM oa1609324

15 Stagno F, Stella S, Spitaleri A, Pennisi MS, Di Raimondo F and Vigneri P: Imatinib mesylate in chronic myeloid leukemia: Frontline treatment and long-term outcomes. Expert Rev Anticancer Ther 16(3): 273-278, 2016. PMID: 26852913. DOI: $10.1586 / 14737140.2016 .1151356$

16 Marin D, Ibrahim AR, Lucas C, Gerrard G, Wang L, Szydlo RM, Clark RE, Apperley JF, Milojkovic D, Bua M, Pavlu J, Paliompeis C, Reid A, Rezvani K, Goldman JM and Foroni L: Assessment of bcr-abll transcript levels at 3 months is the only requirement for predicting outcome for patients with chronic myeloid leukemia treated with tyrosine kinase inhibitors. J Clin Oncol 30(3): 232-238, 2012. PMID: 22067393. DOI: 10.1200/ JCO.2011.38.6565

17 Stella S, Zammit V, Vitale SR, Pennisi MS, Massimino M, Tirro E, Forte S, Spitaleri A, Antolino A, Siracusa S, Accurso V, Mannina D, Impera S, Musolino C, Russo S, Malato A, Mineo G, Musso M, Porretto F, Martino B, Di Raimondo F, Manzella L, Vigneri $\mathrm{P}$ and Stagno F: Clinical implications of discordant early molecular responses in $\mathrm{cml}$ patients treated with imatinib. Int J Mol Sci 20(9), 2019. PMID: 31064152. DOI: 10.3390/ ijms 20092226

18 Stagno F, Vigneri P, Stagno F, Vigneri P, Del Fabro V, Stella S, Berretta S, Massimino M, Tirro E, Messina A and Di Raimondo F: Uncommon long-term survival in a patient with chronic myeloid leukemia. Acta Oncol 48(8): 1215-1216, 2009. PMID: 19863235. DOI: $10.3109 / 02841860903156475$

19 Bhandari A, Rolen K and Shah BK: Management of chronic myelogenous leukemia in pregnancy. Anticancer Res 35(1): 111, 2015. PMID: 25550528.

20 Apperley J: Issues of imatinib and pregnancy outcome. J Natl Compr Canc Netw 7(10): 1050-1058, 2009. PMID: 19930974.

21 Pye SM, Cortes J, Ault P, Hatfield A, Kantarjian H, Pilot R, Rosti G and Apperley JF: The effects of imatinib on pregnancy outcome. Blood 111(12): 5505-5508, 2008. PMID: 18322153. DOI: $10.1182 /$ blood-2007-10-114900

22 Alizadeh H, Jaafar H, Rajnics P, Khan MI and Kajtar B: Outcome of pregnancy in chronic myeloid leukaemia patients treated with tyrosine kinase inhibitors: Short report from a single centre. Leuk Res 39(1): 47-51, 2015. PMID: 25455655. DOI: 10.1016/j.leukres.2014.10.002

23 Baccarani M, Deininger MW, Rosti G, Hochhaus A, Soverini S, Apperley JF, Cervantes F, Clark RE, Cortes JE, Guilhot F, HjorthHansen H, Hughes TP, Kantarjian HM, Kim DW, Larson RA, Lipton JH, Mahon FX, Martinelli G, Mayer J, Muller MC, Niederwieser D, Pane F, Radich JP, Rousselot P, Saglio G, Saussele S, Schiffer C, Silver R, Simonsson B, Steegmann JL, Goldman JM and Hehlmann R: European leukemianet recommendations for the management of chronic myeloid leukemia: 2013. Blood 122(6): 872-884, 2013. PMID: 23803709. DOI: $10.1182 /$ blood-2013-05-501569
24 Sokal JE, Cox EB, Baccarani M, Tura S, Gomez GA, Robertson JE, Tso CY, Braun TJ, Clarkson BD and Cervantes F: Prognostic discrimination in "good-risk" chronic granulocytic leukemia. Blood 63(4): 789-799, 1984. PMID: 6584184.

25 Hasford J, Pfirrmann M, Hehlmann R, Allan NC, Baccarani M, Kluin-Nelemans JC, Alimena G, Steegmann JL and Ansari H: A new prognostic score for survival of patients with chronic myeloid leukemia treated with interferon alfa. Writing committee for the collaborative $\mathrm{cml}$ prognostic factors project group. J Natl Cancer Inst 90(11): 850-858, 1998. PMID: 9625174. DOI: $10.1093 /$ jnci/90.11.850

26 Vigneri P, Stagno F, Stella S, Cupri A, Forte S, Massimino M, Antolino A, Siragusa S, Mannina D, Impera SS, Musolino C, Malato A, Mineo G, Tomaselli C, Murgano P, Musso M, Morabito F, Molica S, Martino B, Manzella L, Muller MC, Hochhaus A and Raimondo FD: High bcr-abl/gus(is) levels at diagnosis of chronic phase CML are associated with unfavorable responses to standarddose imatinib. Clin Cancer Res 23(23): 7189-7198, 2017. PMID: 28928163. DOI: 10.1158/1078-0432.CCR-17-0962

27 Stagno F, Vigneri P, Consoli ML, Cupri A, Stella S, Tambe L, Massimino M, Manzella L and Di Raimondo F: Hyperdiploidy associated with a high bcr-abl transcript level may identify patients at risk of progression in chronic myeloid leukemia. Acta Haematol 127(1): 7-9, 2012. PMID: 21986290. DOI: 10.1159/000330607

28 Douet-Guilbert N, Morel F, Le Charpentier T, Le Bris MJ, Herry A, Morice P, Bourquard P, Abgrall JF, Berthou C and De Braekeleer M: Interphase fish for follow-up of philadelphia chromosome-positive chronic myeloid leukemia treatment. Anticancer Res 24(4): 2535-2539, 2004. PMID: 15330210.

29 Cross NC: Detection of bcr-abl in hematological malignancies by rt-pcr. Methods Mol Med 6: 25-36, 1996. PMID: 21380694. DOI: $10.1385 / 0-89603-341-4: 25$

30 Stella S, Massimino M, Tirro E, Vitale SR, Scalise L, Leotta S, Pennisi MS, Puma A, Romano C, Stagno F, Sapienza G, Milone G and Manzella L: B-all relapses after autologous stem cell transplantation associated with a shift from e1a2 to e14a2 bcrabl transcripts: A case report. Anticancer Res 39(1): 431-435, 2019. PMID: 30591491. DOI: 10.21873/anticanres.13130

31 Hughes T, Deininger M, Hochhaus A, Branford S, Radich J, Kaeda J, Baccarani M, Cortes J, Cross NC, Druker BJ, Gabert J, Grimwade D, Hehlmann R, Kamel-Reid S, Lipton JH, Longtine J, Martinelli G, Saglio G, Soverini S, Stock W and Goldman JM: Monitoring $\mathrm{cml}$ patients responding to treatment with tyrosine kinase inhibitors: Review and recommendations for harmonizing current methodology for detecting bcr-abl transcripts and kinase domain mutations and for expressing results. Blood 108(1): 28-37, 2006. PMID: 16522812. DOI: 10.1182/blood-2006-01-0092

32 Vella V, Puppin C, Damante G, Vigneri R, Sanfilippo M, Vigneri P, Tell G and Frasca F: Deltanp73alpha inhibits pten expression in thyroid cancer cells. Int J Cancer 124(11): 2539-2548, 2009. PMID: 19173293. DOI: 10.1002/ijc.24221

33 Pirosa MC, Leotta S, Cupri A, Stella S, Martino EA, Scalise L, Sapienza G, Calafiore V, Mauro E, Spadaro A, Vigneri P, Di Raimondo F and Milone G: Long-term molecular remission achieved by antibody anti-cd22 and ponatinib in a patient affected by ph'+ acute lymphoblastic leukemia relapsed after second allogeneic hematopoietic stem cell transplantation: A case report. Chemotherapy 63(4): 220-224, 2018. PMID: 30372691. DOI: $10.1159 / 000492941$ 
34 Abruzzese E, Trawinska MM, Perrotti AP and De Fabritiis P: Tyrosine kinase inhibitors and pregnancy. Mediterr J Hematol Infect Dis 6(1): e2014028, 2014. PMID: 24804001. DOI: 10.4084/MJHID.2014.028

35 Kumar S, Apostolova M and Woolley PV: A case of chronic myelogenous leukemia in pregnancy characterized by a complex translocation $\mathrm{t}(9 ; 22 ; 11)(\mathrm{q} 34 ; \mathrm{q} 11.2 ; \mathrm{q} 13)$. Hematol Rep 3(3): e27, 2011. PMID: 22593818. DOI: 10.4081/hr.2011.e27

36 Hughes TP and Ross DM: Moving treatment-free remission into mainstream clinical practice in cml. Blood 128(1): 17-23, 2016. PMID: 27013442. DOI: 10.1182/blood-2016-01-694265

37 Saussele S, Richter J, Guilhot J, Gruber FX, Hjorth-Hansen H, Almeida A, Janssen J, Mayer J, Koskenvesa P, Panayiotidis P, Olsson-Stromberg U, Martinez-Lopez J, Rousselot P, Vestergaard H, Ehrencrona H, Kairisto V, Machova Polakova K, Muller MC,
Mustjoki S, Berger MG, Fabarius A, Hofmann WK, Hochhaus A, Pfirrmann M, Mahon FX and Investigators E-S: Discontinuation of tyrosine kinase inhibitor therapy in chronic myeloid leukaemia (euro-ski): A prespecified interim analysis of a prospective, multicentre, non-randomised, trial. Lancet Oncol 19(6): 747-757, 2018. PMID: 29735299. DOI: 10.1016/S1470-2045(18)30192-X

Received June 10, 2019

Revised July 4, 2019

Accepted July 5, 2019 